BBA 45240

\title{
THE SUBSTRATE-FACILITATED TRANSPORT OF THE GLUCOSE
} \section{CARRIER ACROSS THE HUMAN ERYTHROCYTE MEMBRANE}

\author{
M. LEVINE*, D. L. OXENDER\& AND W. D. STEIN*\& \\ *Department of Chemistry, University of Manchester, Manchester (Great Britain) and \\ $\S$ The Department of Biological Chemistry, The University of Michigan, Ann Arbor, Mich. (U.S.A.)
}

SLMMARY

I. The rate of egress of glucose from human red blood cells into saline media either without sugar or containing glucose, galactose, sorbose or fructose has been determined at $25^{\circ}$ and for glucose or zero sugar at $0^{\circ}$.

2. From these data, using a simplified form of the theoretical analysis of REGEN AND MorGaN ${ }^{13}$, it is shown that the rate of movement across the membrane of the substrate-carrier complex is greater than that of the free carrier, that is, the movement of carrier is facilitated by the substrate.

3. A lower limit of 2.8 is derived for the ratio of these rates of movement.

4. Evidence is presented that the aldoses and ketoses share a common carrier.

\section{INTRODLCTION}

The term "exchange diffusion" when applied to the movement of glucose across the red cell membrane has been used in two senses, with differing molecular bases. The first type of exchange ${ }^{1}$ arises when a shuttling carrier system is shared by two different substrates $\mathrm{A}$ and $\mathrm{B}$ and the carrier system is initially saturated or nearsaturated at both membrane surfaces by the permeating species $\mathrm{A}$. The net transport of $\mathrm{A}$ is thus small and the addition of permeant $\mathrm{B}$ to one side will, by competing for carrier at that face, slow down the movement of $A$ from that face and effectively increase the net transport of $\mathrm{A}$ towards the side to which $\mathrm{B}$ was added. The net flow of $\mathrm{A}$ is increased as a result of the inhibition of the return flow. There is a one-to-one exchange of $\mathrm{B}$ molecules, moving inwards, with $\mathrm{A}$ molecules, moving outwards. We may call this Type-I exchange and the phenomenon will be found for all saturable, shuttling carrier systems ${ }^{2}$.

The second type of exchange ${ }^{3}$ requires an additional condition. The movement of free carrier (not bound to substrate A or B) either cannot occur ${ }^{4}$ or is slower than the movement of the carrier-substrate complex ${ }^{\mathbf{5}, 6}$. Consider a situation where we have permeant $\mathrm{A}$ only on the inside of the cell so that, in the absence of externally added $B$, the return of free carrier is the rate-limiting step in the carrier-mediated efflux of A. If, now, B is added to the medium it will react with the carrier to form the more freely diffusible substrate-carrier complex. The rate of return of carrier is therefore increased and the rate of efflux of $\mathrm{A}$ is likewise augmented. This is Type-II 
exchange and is found only for shuttling carrier systems for which the substrate-carrier complex moves at a faster rate than the free carrier alone. We can call this Type-II exchange or substrate-facilitated carrier transport.

That a shuttling carrier system is concerned in glucose transport is shown by the experiments of ROSENBERG AND WILBRANDT on counter-transport ${ }^{1}$, LEFEVRE AND MCGINniss on unidirectional versus net flow of glucose ${ }^{7}$ and LACKO AND BURGER on exchange of glucose and galactose ${ }^{8,14}$. While these experiments show that Type-I exchange can and does occur, the demonstration of Type-II exchange in red cells has not yet been unequivocally demonstrated. Indeed, LEFEVRE considers his recent results ${ }^{9}$ as grounds for excluding such an interpretation.

The critical experimental condition required here is to ensure that the carrier is far from saturation at the trans face with respect to substrate A whose rate of egress is being measured. This will exclude Type-I exchange. To achieve this condition, efflux experiments were devised in which the loss of glucose from cells was followed into a large volume of medium (effectively an "infinite sink") containing either saline or a sugar ${ }^{\star}$. Then, if the free and bound carriers move at the same rate, the rates of egress in these two situations should be nearly the same. (The rate of egress of glucose would be slightly slower into sugar than into saline since there would be competition for efflux by the sugar that has entered during the time of observation.) If, however, the free carriers move more slowly than the bound carriers, their rate of return will be rate-limiting for egress in the first, but not in the second situation, and the two experimentally determined rates should differ. The rate of egress of glucose into the sugar-containing medium should in fact be the faster. Indeed we find this to be the case.

The sugars chosen were two with low affinities for the carrier, sorbose and fructose, and two high-affinity sugars, galactose and glucose. It has been suggested that the ketoses may not use the same carrier as the aldoses. We will show that sorbose and fructose share a common carrier with glucose.

\section{EXPERIMENTAL}

\section{Materials}

Human red blood cells were obtained from out-of-date transfusion blood kept in acid-citrate-dextrose medium at $4^{\circ}$ and stored from 3 to 6 weeks before use. The cells were washed at least three times in ten times their volume of "buffered saline"- $\mathrm{I} \% \mathrm{NaCl}$ with $25 \mathrm{mM}$ phosphate buffer $(\mathrm{pH} 7.4)$. The plasma and top layer of cells, including most of the leucocytes, were removed in the course of these washings.

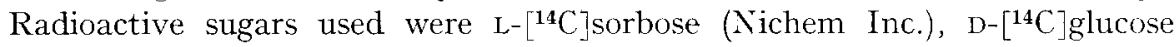
(Radiochemical Centre), D- $\left[{ }^{14} \mathrm{C}\right]$ fructose (Volk) and $\mathrm{D}-\left[{ }^{3} \mathrm{H}\right]$ glucose (Radiochemical Centre).

Unlabelled sugars were D-glucose (AnalaR), D-galactose (BDH), L-sorbose (BDH) and D-fructose (BDH).

* In the apparently similar experiments of LACKO AND BURGER ${ }^{8}$, however, the glucose level in the external medium appears to be about $0.8 \mathrm{mM}$ by the time the first reading of glucose content is made. This concentration is at least twice the value of $K_{\mathrm{m}}$ at that temperature (SEN AND) WIDDAs ${ }^{10}$ ) and thus Type-I exchange cannot be excluded here. LACKo AND Burger do indeed conclude from their results ${ }^{\mathbf{1 4}}$ that there are differences in the rate of movement of bound and free carrier. Their experiments, however, do not demonstrate conclusively that this is so. 


\section{Procedure}

Washed red cells were loaded with glucose by incubation at a haematocrit of 10 \% in a buffered saline medium containing glucose at the desired concentration. Separated, packed cells and media (either buffered saline or buffered saline containing a sugar) were equilibrated separately at $25^{\circ}$.

Medium $(30 \mathrm{ml})$ was added to $0.5 \mathrm{ml}$ glucose-loaded cells for the desired reaction time and the translocation was terminated by the addition of an 8-fold volume of ice-cold $\mathrm{HgCl}_{2}(2 \mathrm{mM}$ in $2 \% \mathrm{NaCl}$ ). After centrifuging and removing the supernatant, SoNogy f filtrates ${ }^{11}$ or trichloroacetic acid extracts of the packed cells were prepared and estimated for sugar content. For the determination of initial glucose content of loaded cells, portions of the incubation medium were mixed directly with the stopping medium, and this mixture then added to the packed, loaded cells. Glucose was analysed by the glucose oxidase method ${ }^{12}$. Isotopically labelled sugars were assayed in the NE 8304 liquid scintillation spectrometer (Nuclear Enterprise G.B. Ltd.) at channel settings adequate to differentiate between the ${ }^{14} \mathrm{C}$ - and ${ }^{3} \mathrm{H}$-radiation levels. A dioxane-based scintillation solvent mixture (Nuclear Enterprise G.B. Ltd. NE 220) was used containing the minimal quantity of ethanol $(2 \%)$ necessary for formation of a single phase.

To determine $K_{1}$ for glucose inhibition of sorbose entry, we proceeded as follows: The cells were equilibrated at a haematocrit of $10 \%$ in a glucose medium of the desired concentration. $\left[{ }^{14} \mathrm{C}\right]$ Sorbose at a final concentration of $2 \mathrm{mM}$ was added to the suspension and the translocation stopped after 5 min at $25^{\circ}$. The amount of sorbose trapped in the extra-cellular space was obtained by mixing the sorbose with the stopping medium before adding it to the equilibrated cells.

\section{RESULTS}

Fig. $I$ is a plot of the loss of glucose in $30 \mathrm{sec}$ at $0^{\circ}$ from cells loaded with $2.6 \mathrm{mM}$ $\left[{ }^{3} \mathrm{H}\right]$ glucose, the external level of glucose varying from o to $64 \mathrm{mM}$. This was an earlier experiment ${ }^{\star}$ and shows the increase in rate of egress of glucose as the external level of glucose is increased.

The effect of a saturating concentration of galactose in the external medium on glucose exit is depicted in Fig. 2. The per cent of glucose remaining in the cells after I $5 \mathrm{sec}$ at $25^{\circ}$ is shown as it varies with the glucose concentration of the loaded cells. The results given are from one of two such experiments. Glucose egress into saline is represented in Curve I while in Curve 2 we record the egress of glucose into $200 \mathrm{mM}$ galactose. From the figure we can see that where the concentration of glucose inside the cell is high initially, the rate of exit into the galactose is faster than into medium free of galactose. Competition for exit between internal glucose and the galactose that has entered the cells during the time of observation will, however, decrease efflux of glucose; at the lower concentrations of glucose this competition predominates over the acceleration of egress due to Type-II exchange. In Fig. 3, we can compare egress in $5 \mathrm{sec}$ from $0-100 \mathrm{mM}\left[{ }^{14} \mathrm{C}\right]$ glucose-loaded cells into saline (Curve I) with egress into equimolar $\left[{ }^{12} \mathrm{C}\right]$ glucose (Curve 2) and into $200 \mathrm{mM}$ galactose (Curve 3 ). These results are from two such experiments in good agreement. A third

* This experiment was carried out at the University of Michigan with the technical assistance of Miss G. FranKE. 
experiment, in which the volume of these suspending media was increased Io-fold to ensure that there could be no return flow of glucose, produced substantially similar results. The limiting velocities reached from high concentrations of glucose inside

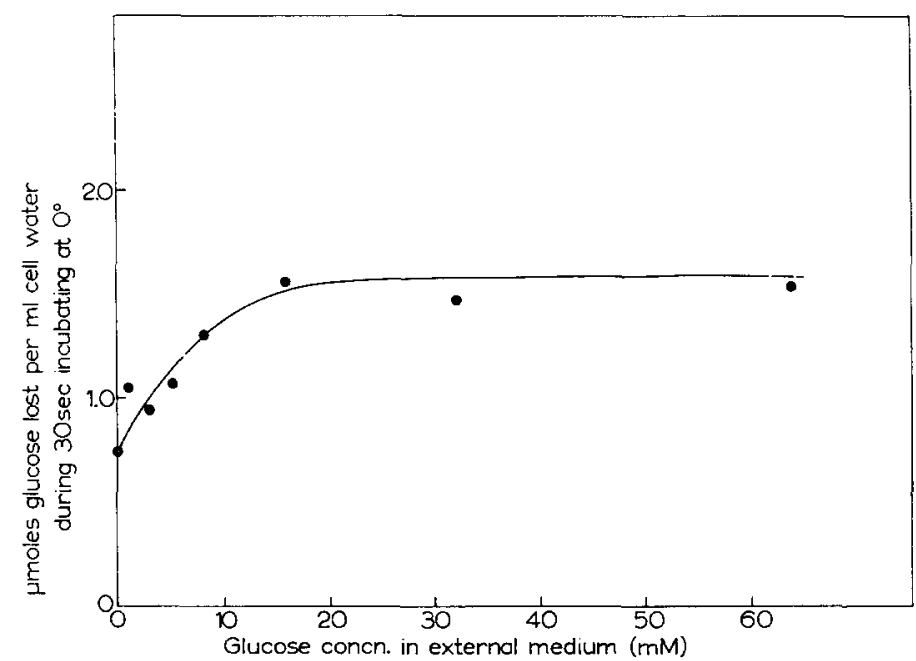

Fig. I. $\left[{ }^{3} \mathrm{H}\right]$ Glucose efflux into unlabelled glucose.

the cells appear to differ in each case. However, it is shown that the $V_{\max }$ for glucose into galactose is equal to the $V_{\max }$ for glucose into equimolar glucose. From the ratios of the maximum velocities, the relative rates of movement of substrate-carrier complex to free carrier is determined. The details appear in the APPENDIX, Part III.

Observations of efflux of glucose into medium containing a sugar with low affinity for the carrier can be seen in Tables I and II. Table I records the concentrations of glucose remaining in the cells after efflux for $15 \mathrm{sec}$ and $60 \mathrm{sec}$ into media containing $500 \mathrm{mM}$ sorbose, $250 \mathrm{mM}$ sorbose in buffered saline or buffered saline without sugar

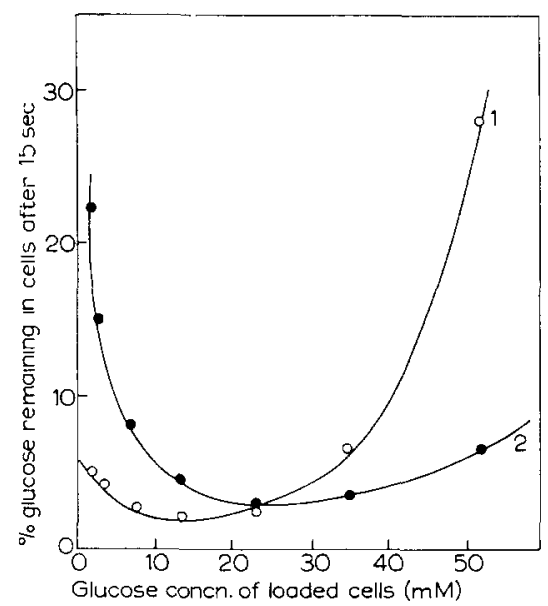

Fig. 2. Effect of galactose on glucose egress. Curve I (open circles), glucose into saline; Curve 2 (solid circles), glucose into galactose medium.

Biochim. Biophys. Acta, Iog (I965) 15 I-I63 
(all adjusted to equivalent tonicity). The experiment at $\mathrm{I}_{5} \mathrm{sec}$ is one of two with similar results. The glucose content of the loaded cells at zero time was found to be I03 mM.

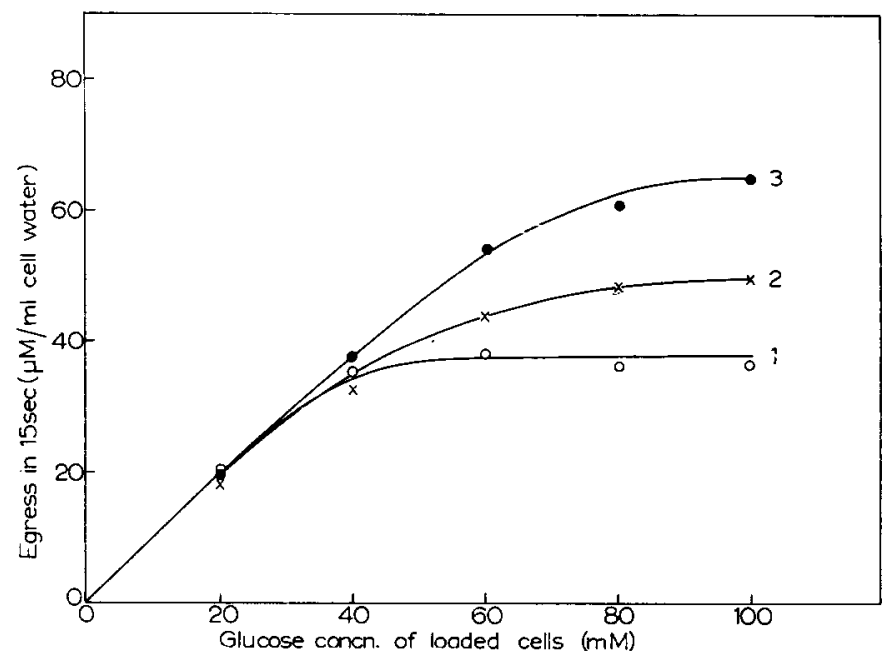

Fig. 3. Effect of galactose and equimolar $\left[^{12} \mathrm{C}\right]$ glucose on $\left.{ }^{14} \mathrm{C}\right]$ glucose egress. Curve I (open circles), $\left[{ }^{14} \mathrm{C}\right]$ glucose into saline; Curve 2 (crosses), $\left[{ }^{14} \mathrm{C}\right]$ glucose into equimolar $\left[{ }^{12} \mathrm{C}\right]$ glucose; Curve 3 (solid circles), $\left[{ }^{14} \mathrm{C}\right.$ glucose into $200 \mathrm{mM}$ galactose.

TABLE I

GLUCOSE (mM) REMAINING IN CELLS AFTER $t$ SEC AT $25^{\circ}$

Glucose concentration of loaded cells at zero time $=103 \mathrm{mM}$.

\begin{tabular}{llc} 
& $t=I .5 \mathrm{sec}$ & $t=60 \mathrm{sec}$ \\
\hline Into 500 $\mathrm{mM}$ sorbose & 84 & $\mathbf{2 2}$ \\
Into 250 mM sorbose & 76 & $\mathrm{I} 2$ \\
Into saline & 66 & 7.2 \\
\hline
\end{tabular}

\section{TABLE II}

GLUCOSE (mM) REMAINING IN CELLS AFTER $t$ SEC AT $25^{\circ}$

Glucose concentration of loaded cells at zero time $=70 \mathrm{mM}$. Figures in brackets are corrections for volume changes.

\begin{tabular}{llr} 
& $t=I_{5} \mathrm{sec}$ & $t=60 \mathrm{sec}$ \\
\hline Into 5oo $\mathrm{mM}\left[{ }^{14} \mathrm{C}\right]$ fructose & $50(46)$ & I I $\quad(9.0)$ \\
Into 250 mM $\left[{ }^{14} \mathrm{C}\right]$ fructose & $47(47)$ & $4.8(5 \cdot 3)$ \\
Into saline & $3^{8}(42)$ & $2.0(2.5)$
\end{tabular}

Similarly in Table II we present data on the glucose remaining after $\mathrm{I} 5 \mathrm{sec}$ and $60 \mathrm{sec}$ of efflux at $25^{\circ}$ into media containing $500 \mathrm{mM}\left[{ }^{14} \mathrm{C}\right]$ fructose, $250 \mathrm{mM}$ $\left[{ }^{14} \mathrm{C}\right]$ fructose or buffered saline without sugar (all media of equivalent tonicity). The concentration of glucose in the cells at zero time was $70 \mathrm{mM}$. Corrections have been 
made for the probable cell volume changes that could have occurred during the course of this experiment and these corrected data are given in the parentheses in Table II.

The volume of the cell water per unit packed cells at time $t$ is given by

$$
V=\frac{V(o)\left\{\left[F_{0}+S_{0}\right]-[G(\mathrm{o})]\right\}+a+b}{\left[F_{0}+S_{0}\right]}
$$

where $V(o)$ is the volume of cell water per unit packed cells at zero time, $\left[F_{0}+S_{0}\right]$ the osmolar concentration in the outside medium of fructose $\left(F_{0}\right)$ and other solutes $\left(S_{0}\right) .\left[F_{0}+S_{0}\right]$ remains constant since the volume is infinitely large. $[G(0)]$ is the glucose concentration inside the cell at zero time while $a$ and $b$ are the amounts of glucose and fructose respectively inside the cells at time $t$. The derivation of these relationships is contained in the APPENDIX, Part IV.

For the case of egress of glucose into saline, the cell shrinks but for glucose into $25^{\circ} \mathrm{mM}$ fructose, the amount of fructose entering was equal to the glucose lost and hence there was no volume change. In the case of glucose into $500 \mathrm{mM}$ fructose, there was apparently a larger amount of fructose in the cells than glucose lost resulting in a small volume increase.

Fig. 4 shows the effect of glucose present in the medium on the rate of entry of $\left[{ }^{14} \mathrm{C}\right]$ sorbose into the cells at $25^{\circ}$. This plot of the counts per $200 \mathrm{sec}$ of $\left[{ }^{14} \mathrm{C}\right]$ sorbose

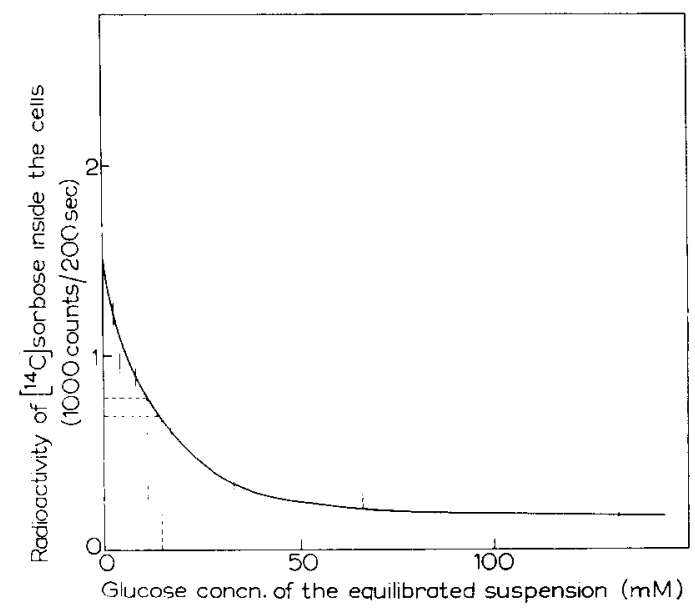

Fig. 4. Glucose inhibition of sorbose permeability.

inside the cells against glucose concentration in the medium, leads to the value of $13 \pm 2 \mathrm{mM}$ for $K_{\mathrm{i}}$, the constant expressing the affinity of glucose for the sorbose carrier.

DISCUSSION

Figs. I-3 show clearly that Type-II exchange occurs in the glucose transport system of the human red blood cell at $0^{\circ}$ and at $25^{\circ}$. A theoretical analysis of the equations governing transport for the case where the rates of diffusion of free carrier and of substrate-carrier complex are unequal has been derived by REGEN AND 
Morgan $^{13}$, based on the model depicted in Fig. 5 (see APPendix, Part I). These authors derive the rate equations for the very general case where the pairs of constants $k_{2}$ and $k_{-2}, k_{4}$ and $k_{-4}, k_{1}$ and $k_{-3}, k_{-1}$ and $k_{3}$ in Fig. 5 are unequal and where no restrictions are placed on the magnitude of these constants. If, however, we assume

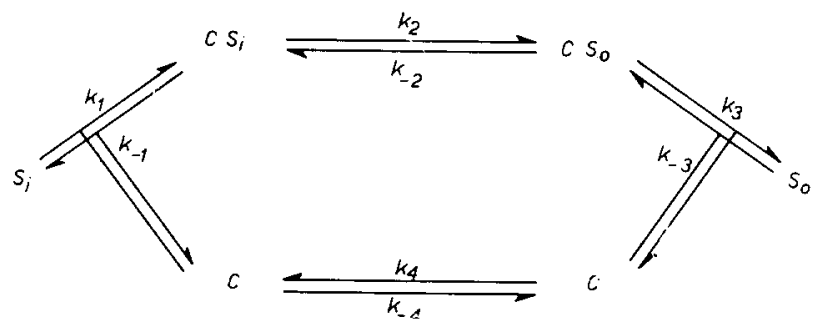

Fig. 5. Model of a shuttling carrier. $C$, free carrier; $S_{1}$ and $S_{\mathbf{0}}$ are sugars inside and outside the cell, respectively; $C S$, complex of sugar plus carrier. Similar to the scheme of REGEN AND MoRGAN ${ }^{13}$.

that the membrane is symmetrical with respect to the glucose-transport system, the derived equations assume a much simpler form (APPENDIX, Part II). These forms derived by making the substitutions $k_{2}=k_{-2}, k_{4}=k_{-4}, k_{1}=k_{-3}, k_{-1}=k_{3}$ in the equations of REGEN AND MORGAN, lead to a value for the ratio of $k_{2} / k_{4}$, the velocity of loaded versus unloaded carriers. We obtain the result that

$$
\frac{V_{\text {max., equil. }}}{V_{\max ., \text { zero }}}=\frac{\mathbf{I}+\frac{k_{2}}{k_{4}}\left(\frac{k_{3}}{2 k_{2}}+k_{3}\right)}{2}
$$

where $V_{\max .,}$ equil. is the maximum velocity of unidirectional transport of sugar into an equilibrium concentration of sugar, $V_{\max }$, zero the maximum velocity of transport of sugar into a sugar-free medium.

Now, $V_{\max .,}$ equil. $/ V_{\max . \text {, zero }}$ can be determined experimentally from the data

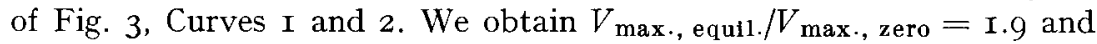

$$
\frac{k_{2}}{k_{4}}\left(\frac{k_{3}}{2 k_{2}+k_{3}}\right)=2.8
$$

The method of obtaining this value is given in the APPEndix, Part III where $V_{\text {max }}$. values are shown in Table III.

It is generally assumed that the rate of diffusion of free and bound carrier across the membrane is rate-limiting for transport as compared with the rates governing the equilibria at the membrane surface i.e. from Fig. $5, k_{3} \gg k_{2}$. If this assumption is valid then the value 2.8 can be equated to $k_{2} / k_{4}$, the relative velocities of diffusion of loaded and unloaded carriers. If $k_{2}$ is of the same order of magnitude as $k_{3}$, however, the experimentally derived value underestimates $k_{2} / k_{4}$. Therefore it is clear that, if the membrane is symmetrical in respect to glucose transport, then from the data of Fig. 3 the relative rate of diffusion of the glucose-carrier complex to the free carrier is at least 2.8 .

In a similar fashion the data of Fig. 2 and Fig. 3 (Curves I and 3 ) can be interpreted in terms of these simpler forms of the equations of REGEN AND MORGAN. The maximum velocity of egress into an external medium effectively saturated with 
the exchanging sugar proves to be identical with that for egress into an equilibrium concentration of sugar ( $V_{\max .,}$ equil., above), so that the relation

$$
\frac{V_{\text {max }} \text { into an infinite concentration of exchanging sugar }}{V_{\text {max. }} \text { into zero sugar }}=\frac{I+\frac{k_{2}}{k_{4}}\left(\frac{k_{3}}{2 k_{2}}+k_{3}\right)}{2}
$$

is obtained. From the data of Fig. 3 we find

$$
\frac{V_{\max } \text { for glucose into galactose }}{V_{\max } \text { for glucose into zero sugar }}=\mathrm{I} .9
$$

from which $k_{2} / k_{4}$ is at least 2.8 at $25^{\circ}$.

At both $0^{\circ}$ and $25^{\circ}$ for human red blood cells, therefore, the rates of diffusion of the loaded and unloaded carriers appear to be unequal.

BRITTON $^{15}$ in his work on the permeability of the human red cell to labelled glucose at $37^{\circ}$ compares his results for the initial rate of entry into sugar-free cells (0.0I75 isotonic units/sec) with the glucose flux for cells equilibrated with I33 mM glucose $(0.052$ isotonic units/sec). These should be identical if bound and free carrier have the same rates. The difference is attributed to different methods used and the very rapid movements involved. The author, however, comments on the possibility that the flux could increase as the internal concentration of glucose rises. From the ratio of these rates, the value for $k_{2} / k_{4}$ equals 5 . BRITTON finds that the glucose flux reaches a limiting velocity in the concentration range $70-267 \mathrm{mM}$ at $37^{\circ}$ which is in fair agreement with our results at $25^{\circ}$.

REgen AND MoRgan, working in the range of 0.8 to $46 \mathrm{mM}$ at $37^{\circ}$ with rabbit red cells, find the rates identical within experimental error. It may well be, however, that at $37^{\circ}$, this concentration range does not reach high enough levels to exhibit the phenomenon.

We can comment further on the relations between aldose and ketose transport. From Tables I and II it is clear that the presence of sorbose or fructose in the medium does not increase the rate of exit of glucose. In fact the rate of glucose egress into saline is somewhat faster than into sorbose or fructose at these concentrations. There are three possible explanations for this apparent slowing down of egress, namely:

(i) Differences in cell volumes. Sorbose or fructose entering the cell compensates for glucose egress thus preventing the cell shrinkage that occurs when glucose is transported into saline only. Any shrinkage will concentrate the remaining glucose and maintain the existing concentration gradient. Corrections for the volume changes (figures in parentheses, Table II) assuming that the cells behave as an osmometer, indicate that some of the apparent slowing in the rate of egress can be accounted for in this fashion.

(ii) Some part of the slowing of egress may be due to competition for efflux by the sorbose or fructose that has entered. Because of the low affinities of these sugars, however, this contribution will be very small.

(iii) The possibility has been considered that the rate of diffusion of the sorbosecarrier complex may be slower than that of the free carrier. When a $(200 \mathrm{mM})$ sucrose medium in saline buffer at tonicity equivalent to the sugar-free saline was substituted for the saline, it also slowed the rate of egress of glucose. This effect has been found for other disaccharides. LACKo AND BURGER ${ }^{16}$ found that maltose, cellobiose and 
isomaltose in the medium inhibited the exchange transfer between glucose and galactose.

While the rate of egress of glucose is not increased by the presence of sorbose or fructose externally, it has been found that $\left[{ }^{14} \mathrm{C}\right]$ fructose entry is faster into glucoseloaded cells than into sugar-free cells, suggesting once again that glucose and fructose share a common carrier.

In an experiment in which the permeability of $\mathrm{L}-\left[6-{ }^{14} \mathrm{C}\right]$ sorbose in the presence of varying concentrations of glucose was measured, $K_{1}$ for glucose inhibition of sorbose entry was found to be $13 \pm 2 \mathrm{mM}$. This result is higher than our value of $K_{\mathrm{m}}$ for glucose entry (unpublished) but is evidence that these two sugars also share a common carrier. Clearly, therefore, it is because of their high values of $K_{\mathrm{m}}$ that neither fructose nor sorbose can increase the rate of glucose exit at the concentrations that can be used experimentally, rather than, as suggested by LACKO AND BURGER ${ }^{8}$, that the ketoses and aldoses are transported by different carrier species.

\section{APPENDIX}

\section{General rate equation of REGEN AND MORGAN}

The efflux equation of REGEN AND MORGan is given by

$$
v_{S-}=\frac{\left[S_{\mathbf{i}}\right] F_{S}}{\mathrm{I}+\frac{\left[S_{\mathrm{i}}\right]}{B_{S}}+\frac{\left(\left[S_{\mathrm{i}}\right]-\left[S_{\mathrm{o}}\right]\right) M_{S I}}{\mathrm{I}+\left[S_{\mathrm{o}}\right] / R_{S}}}
$$

where $v_{s-}$ is the unidirectional efflux of sugar $S$, and $\left[S_{\mathbf{i}}\right]$ and $\left[S_{\mathrm{o}}\right]$ are concentrations in molar units of sugar inside and outside the cell, respectively. Also

$$
F_{S}=[\operatorname{tot} C] r_{S} \frac{k_{-4}}{\left(k_{4}+k_{-4}\right)}
$$

where $[$ tot $C$ ] is the total carrier concentration in moles divided by dry cell mass,

$$
\begin{aligned}
& r_{S}=\frac{k_{-3} k_{-2} k_{-1}}{k_{2} k_{3}+k_{-1} k_{-2}+k_{-1} k_{3}} \\
& B_{S}=\frac{k_{-1}\left(k_{4}+k_{-4}\right) k_{-2}}{k_{1} k_{4}\left(k_{2}+k_{-2}\right)}=\frac{k_{3}\left(k_{4}+k_{-4}\right) k_{2}}{k_{-3} k_{-4}\left(k_{2}+k_{-2}\right)} \\
& M_{S I}=\frac{r}{k_{4}+k_{-4}} \cdot \frac{k_{2} k_{3}-k_{-4}\left(k_{2}+k_{-2}+k_{3}\right)}{k_{2} k_{3}} \\
& R_{S}=\frac{k_{-4}}{f_{S}}=\frac{k_{4}}{r_{S}}=\text { flux ratio constant } \\
& t_{S}=\frac{k_{1} k_{2} k_{3}}{k_{2} \frac{k_{3}+k_{-1} k_{-2}+k_{-1} k_{3}}{2}}
\end{aligned}
$$

When $\left[S_{0}\right]=\left[S_{1}\right]$, that is, efflux into equilibrium concentration of sugar,

$$
v_{S-}=\frac{\left[S_{i}\right] F_{S}}{\mathbf{I}+\frac{\left[S_{\mathbf{i}}\right]}{B_{S}}}=B_{S} F_{S} \text { as }\left[S_{\mathbf{i}}\right] \rightarrow \infty
$$


When $\left[S_{0}\right]=$ zero, that is, efflux into sugar-free medium,

where

$$
v_{S-}=\frac{\left[S_{\mathbf{i}}\right] F_{S}}{\mathrm{I}+\frac{\left[S_{\mathbf{i}}\right]}{K_{S I}}}=K_{S I} F_{S} \text { as }\left[S_{\mathrm{i}}\right] \rightarrow \infty
$$

$$
K_{S I}=\frac{\left(k_{4}+k_{-4}\right)\left(k_{9} k_{3}+k_{3} k_{-1}+k_{-1} k_{-2}\right)}{k_{-3}\left(k_{-2} k_{-1}+k_{-2} k_{-4}+k_{-1} k_{-4}+k_{-4} k_{2}\right)}
$$

For the special case where $k_{2}=k_{-2}, k_{4}=k_{-4}, k_{-1}=k_{3}$, and $k_{1}=k_{-3}$,

$$
\frac{V_{\text {max. into equil. sugar }}}{V_{\text {max. }} \text { into zero sugar }}=\frac{B_{S}}{K_{S}}=\frac{\mathrm{I}+\frac{k_{2}}{k_{4}}\left(\frac{k_{3}}{2 k_{2}+k_{3}}\right)}{2}
$$

If $k_{3} \gg k_{2}$, this expression reduces to

$$
\frac{\mathrm{I}+k_{2} / k_{4}}{2}
$$

where $k_{2} / k_{4}$ equals the relative rates of bound and free carrier.

\section{Special case}

Derivation of $k_{2} / k_{4}$, the relative rates of movement of bound and free carrier, assuming that the carrier sites are symmetrically distributed, that is, $k_{2}=k_{-2}, k_{4}=k_{-_{4}}$, $k_{-3}=k_{1}, k_{-1}=k_{3}$ and $k_{3} \gg k_{2}$.

On the inside

$$
C_{\mathbf{i}}+S_{\mathrm{i}} \rightleftharpoons C S_{\mathrm{i}} ; \frac{\left[C_{\mathbf{i}}\right]\left[S_{\mathrm{i}}\right]}{\left[C S_{\mathrm{i}}\right]}=K
$$

and on the outside

$$
C_{0}+S_{0} \rightleftharpoons C S_{0} ; \frac{\left[C_{0}\right]}{\left[C S_{0}\right]}=K
$$

where

$$
K=\frac{k_{-1}}{k_{1}}=\frac{k_{3}}{k_{-3}}
$$

Subscripts o and i indicate outside and inside of the cell ; $S$, sugar; $C$, free carrier; $C S$ sugar-carrier complex.

$$
\text { Total carrier }(\text { tot } C) \text { concentration }=\left[C S_{0}\right]+\left[C S_{\mathbf{i}}\right]+\left[C_{\mathbf{i}}\right]+\left[C_{\mathbf{0}}\right]
$$

and

$$
k_{2}\left[C S_{\mathrm{i}}\right]+k_{4}\left[C_{\mathrm{j}}\right]=k_{2}\left[C S_{\mathrm{O}}+k_{4}\left[C_{\mathrm{o}}\right]\right.
$$

By substitution for $\left.{ }^{C} C S_{\mathrm{i}}\right]$ and $\left[C S_{\mathrm{o}}\right]$ in Eqns. I and 2 we obtain

$$
[\operatorname{tot} C]=\frac{\left[C_{0}\right]\left[S_{0}\right]}{K}+\frac{\left[C_{\mathbf{i}}\right]\left[S_{\mathbf{i}}\right]}{K}+\left[C_{\mathbf{i}}\right]+\left[C_{0}\right]
$$

and

$$
k_{2} \frac{\left[C_{\mathrm{i}}\right]\left[S_{\mathrm{i}}\right]}{K}+k_{4}\left[C_{\mathrm{i}}\right]=k_{2} \frac{\left[C_{0}\right]\left[S_{0}\right]}{K}+k_{4}\left[C_{0}\right]
$$




$$
\left[C_{\mathrm{o}}\right]=\left[C_{\mathrm{i}}\right] \frac{k_{2} \frac{\left[S_{\mathrm{i}}\right]}{K}+k_{4}}{k_{2} \frac{\left[S_{\mathrm{o}}\right]}{K}+k_{4}}
$$

By substituting for $\left[C_{0}\right]$ into Eqn. 3 we have

$$
\left[C_{\mathrm{i}}\right]=\frac{\left(k_{2}\left[S_{0}\right]+k_{4} K\right) K[\operatorname{tot} C]}{\left(K+\left[S_{\mathrm{i}}\right]\right)\left(k_{2}\left[S_{\mathrm{o}}\right]+k_{4} K\right)+\left(K+\left[S_{\mathrm{o}}\right]\right)}\left(k_{2}\left[S_{\mathrm{i}}\right]+\overline{\left.k_{4} K\right)}\right.
$$

The amount of $C S_{1}$ crossing unit area per unit time equals

$$
k_{2}\left[C S_{\mathbf{i}]}\right]=k_{2}\left(\left[C_{\mathrm{i}}\right] \frac{\left[S_{\mathbf{i}}\right]}{K}\right)=\frac{\left(\frac{k_{2}}{k_{4}}\left[S_{\mathrm{o}}\right]+K\right) k_{2}\left[S_{\mathrm{i}}\right][\operatorname{tot} C]}{2 K^{2}+K\left(\left[S_{\mathrm{i}}\right]+\left[S_{\mathrm{o}}\right]\right)\left(\mathrm{I}+k_{2} / k_{4}\right)+2 \frac{k_{2}}{k_{4}}\left[S_{\mathbf{i}}\right]\left[S_{0}\right]}
$$

Similarly

$$
\begin{aligned}
& k_{2}\left[C S_{0}\right]=\frac{\left(\frac{k_{2}}{k_{4}}\left[S_{\mathrm{i}}\right]+K\right) k_{2}\left[S_{\mathrm{o}}\right][\operatorname{tot} C]}{2 K^{2}+K\left(\left[S_{\mathrm{i}}\right]+\left[S_{\mathrm{o}}\right]\right)\left(\mathrm{I}+k_{2} / k_{4}\right)+2 \frac{k_{2}}{k_{4}}\left[S_{\mathrm{i}}\right]\left[S_{\mathrm{o}}\right]} \\
& \begin{aligned}
& \therefore \text { Net flux }=-K k_{2}[\operatorname{tot} C]\left(\left[S_{\mathrm{o}}\right]-\left[S_{\mathrm{i}}\right]\right) \\
& 2 K^{2}+K\left(\left[S_{\mathrm{i}}\right]+\left[S_{\mathrm{o}}\right]\right)\left(\mathrm{I}+k_{2} / k_{4}\right)+2 \frac{k_{2}}{k_{4}}\left[S_{\mathrm{i}}\right]\left[S_{\mathrm{o}}\right]
\end{aligned} \\
& \text { When }\left[S_{\mathrm{o}}\right] \text { equals zero, flux }=\frac{\frac{k_{2}}{\mathrm{I}+\frac{k_{2} / k_{4}}{2 K}}[\operatorname{tot} C]\left[S_{\mathrm{i}}\right]}{\mathrm{I}+k_{2} / k_{4}}+\left[S_{\mathrm{i}}\right]
\end{aligned}
$$$$
\text { When }\left[S_{0}\right] \text { is infinite, flux }=\frac{\frac{1}{2} k_{2}[\operatorname{tot} C]\left[S_{\mathrm{i}}\right]}{K\left(\frac{1+k_{2} / k_{4}}{2 k_{2} / k_{4}}\right)}+\left[S_{1}\right]
$$$$
\frac{V_{\max } \text {. into a saturating exchanging sugar }}{V_{\max } \text { into zero sugar }}=\frac{\mathbf{I}+k_{2} / k_{4}}{2}
$$

\section{Method of calculating $k_{2} / k_{4}$ from the data of Fig. 3}

For glucose exit into galactose or into an equilibrium of isotopic glucose we assume that there is a one-for-one exchange of molecules and that the galactose or glucose isotope that has entered during the time of observation will compete for exit.

We have, then, at time $t$ : concentration inside of glucose $=G(t)$, that of inhibitor $=I(t)$; concentration outside of glucose is zero (infinite dilution), and that of inhibitor $=I_{o}$ which is constant. Then rate of egress of glucose can be expressed by

$$
\frac{\mathrm{d} G(t)}{\mathrm{d} t}=\frac{-G(t) V_{\max }}{G(t)+k_{G}\left(\mathrm{I}+\frac{I(t)}{k_{I}}\right)}
$$


where $k_{G}, k_{I}$ are affinity constants for glucose and inhibitor respectively and $V_{\max }$. is the limiting velocity of movement across the membrane. $I(t)=G_{\mathrm{m}}-G(t)$ as assumed above where $G_{\mathrm{m}}=G(t)$ at $t=0$. By substituting for $I(t)$ and integrating we obtain

$$
\left(G_{\mathrm{m}}-G(t)\right)\left(\mathrm{I}-k_{G} / k_{I}\right)+\left(k_{G}+k_{G} G_{\mathrm{m}} / k_{I}\right) \ln \frac{G_{\mathrm{m}}}{G(t)}=V_{\max .} t
$$

which is the equation for Curve 3 in Fig. 3.

For isotope exchange, where $k_{G}$ equals $k_{I}$, this reduces to

$$
\left(k_{G}+G_{\mathrm{m}}\right) \ln \frac{G_{\mathrm{m}}}{G(t)}=V_{\text {max. }} .
$$

which is represented by Curve 2 of Fig. 3. For glucose into saline, the integrated rate equation is

$$
\left(G_{\mathrm{m}}-G(t)\right)+k_{G} \ln \frac{G_{\mathrm{m}}}{G(t)}=V_{\max .} t
$$

describing Curve I in Fig. 3. Here, $G_{\mathrm{m}}-G(t)$ is constant at high $G_{\mathrm{m}}$ where $k_{G} \ln$ $G_{\mathrm{m}} / G(t)$ is relatively small.

\begin{tabular}{|c|c|c|c|c|c|}
\hline Curve & $G_{m}(m M)$ & $V_{\max }($ mmoles/min) & & $k_{G}=I m M$ & $k_{G}=\operatorname{to} m M$ \\
\hline \multirow[t]{4}{*}{ I } & IOO & $\mathrm{I}_{50}+\mathrm{I} .8 k_{G}$ & & $I_{52}$ & I 68 \\
\hline & 75 & ${ }^{1} 5^{\circ}+2.8 k_{G}$ & & I 53 & 178 \\
\hline & 5o & $\mathrm{x}_{50}+5.5 k_{G}$ & & I 55 & 202 \\
\hline & & & Mean & I 53 & I 82 \\
\hline \multirow[t]{4}{*}{2} & Ioo & $277+2.8 k_{G}$ & & 280 & 304 \\
\hline & 75 & $306+4.0 k_{G}$ & & 310 & $34^{6}$ \\
\hline & 56 & $308+5 \cdot 5 k_{G}$ & & $3^{\mathrm{I}} 4$ & $36_{3}$ \\
\hline & & & Mean & $3 \circ \mathrm{I}$ & $33^{8}$ \\
\hline \multirow{4}{*}{$\begin{array}{l}3 \\
\left(\frac{k_{G}}{k_{I}}=0.2\right)\end{array}$} & IOO & $292+4.2 k_{G}$ & & 296 & 334 \\
\hline & 84 & $294+5.5 k_{G}$ & & 300 & 349 \\
\hline & 60 & $273+8.6 k_{G}$ & & 282 & 359 \\
\hline & & & Mean & 293 & 347 \\
\hline
\end{tabular}

TABLE III

TyPical Values of $V_{\text {max }}$ ObTained from curves in Fig. 3

At high concentrations of $G_{\mathrm{m}}$, the data shown in Table III give a reasonable fit of the above theoretical equations. At values of $k_{G}$ for glucose between I and Io, the ratio

$$
\frac{V_{\max } \text { for glucose into an exchanging sugar or isotopic glucose }}{V_{\max } \text { for glucose into saline }}=\mathbf{I} .9
$$

The ratio of the rate of bound carrier to free carrier $k_{2} / k_{4}$ will have a lower limit of 2.8 . 


\section{Method for calculating volume changes}

The method of estimating volume changes assumes that the membrane is freely permeable to water and the cell behaves as an osmometer. Suppose that at time $t\left[S_{\mathrm{i}}(t)\right]$ is the osmolar concentration of molecules inside the cell that cannot permeate the membrane, $[G(t)]$ the concentration of glucose inside the cell and $\left[F_{1}(t)\right]$ the concentration of fructose inside the cell. $\left[F_{0}+S_{0}\right]$ is the osmolar concentration of fructose and other solutes in the medium. This remains constant since the volume of medium is large relative to the cells. $V(t)$ is the volume of cell water per unit packed cells. We have the amount of glucose inside at time $t$ is $a(t)=[G(t)] V(t)$ and the amount of fructose inside at time $t$ is $b(t)=\left[F_{1}(t)\right] V(t)$. Then

$$
\left[F_{\mathrm{o}}+S_{\mathbf{0}}\right]=[G(t)]+\left[F_{\mathbf{i}}(t)\right]+\left[S_{\mathbf{i}}(t)\right]
$$

At time $t=0$,

$$
\begin{aligned}
& {\left[F_{\mathrm{i}}(\mathrm{o})\right]=0 ; \quad\left[F_{\mathrm{o}}+S_{\mathrm{o}}\right]=[G(\mathrm{o})]+\left[S_{\mathbf{i}}(0)\right]} \\
& V(\mathrm{o})\left[S_{\mathrm{i}}(\mathrm{o})\right]=V(t)\left[S_{\mathrm{i}}(t)\right] \\
& \quad \cdot V(t)=\frac{V(\mathrm{o})\left[S_{\mathrm{i}}(\mathrm{o})\right]}{\left[S_{\mathrm{i}}(t)\right]}=\frac{V(\mathrm{o})\left(\left[F_{\mathrm{o}}+S_{\mathrm{o}}\right]-[G(\mathrm{o})]\right)}{[S \mathrm{Si}(t)]} \\
& \quad=\frac{V(\mathrm{o})\left(\left[F_{\mathrm{o}}+S_{\mathrm{o}}\right]-[G(\mathrm{o})]\right)}{\left[F_{\mathrm{o}}+S_{\mathrm{o}}\right]-[G(t)]-\left[F_{\mathrm{i}}(t)\right]}=\frac{V(\mathrm{o})\left(\left[F_{\mathrm{o}}+S_{\mathrm{o}}\right]-[G(\mathrm{o})]\right)}{\mathrm{I}}
\end{aligned}
$$

Solving for $V(t)$,

$$
V(t)=\frac{V(\mathrm{o})\left(\left[F_{\mathrm{o}}+S_{\mathrm{o}}\right]-[G(\mathrm{o})]\right)+a+b}{\left[F_{\mathrm{o}}+S_{\mathrm{o}}\right]}
$$

where $a=a(t)$ and $b=b(t)$.

\section{REFERENCES}

I T. Rosenberg and W. Wilbrandt, J. Gen. Physiol, 4 I (I957) 289.

2 H. N. Christensen, Biological Transport, W. A. Benjamin, New York, I962, p. 2 r.

3 E. Heinz and P. Walsh, J. Biol. Chem., 233 (1958) I 488.

4 H. H. Ussing, Nature, I6o (I947) 262.

5 J. A. JAcQuez, Proc. Natl. Acad. Sci. U.S., 47 (Ig6r) I 53.

6 J. A. Jacquez, Am. J. Physiol., 200 (196I) Io63.

7 P. G. LeFevre and G. F. McGinniss, J. Gen. Physiol., 44 (1960) 87.

8 I. LACKO AND M. Burger, Nature, IgI (I96I) $88 \mathrm{I}$.

9 P. G. LeFevre, J. Gen. Physiol., 46 (I963) $72 \mathrm{I}$.

io A. K. Sen and W. F. Widdas, J. Physiol. London, i6o (1962) 392.

I I M. Somogyi, J. Biol. Chem., I6o (1945) 69.

I2 M. E. Washko and E. W. RICE, Clin. Chem., 7 (I96I) 542.

i 3 D. M. Regen and H. E. Morgan, Biochim. Biophys. Acta, 79 (1964) I5I.

I4 L. LaCko aNd M. Burger, J. Biol. Chem., 238 (I963) 3478.

I5 H. G. Brition, J. Physiol. London, I7o (I964) I.

I6 L. LACko AND M. BuRger, Biochem. J., 83 (1962) 622. 